\title{
From Bench to Bedside: Therapies for Acute Respiratory Distress Syndrome
}

Raquel Guillamat-Prats*, Marta Camprubí-Rimblas and Antonio Artigas

Critical Care Center, Parc Tauli, numero 1, Sabadell, Barcelona 08208, Spain and CIBERES

\begin{abstract}
Acute lung injury (ALI) and its severe form, acute respiratory distress syndrome (ARDS), is originated by multiple insults. ARDS is a significant source of morbidity and mortality in the critically ill patient population. The complex physiopathology of ALI/ARDS is characterized by inflammation, coagulation pathways dysregulation, injury of endothelial and epithelial barrier and pulmonary edema. Altogether provides a wide range of targets that offers multiple therapeutic options. In the last years, multiple preclinical and clinical studies have been performed for the treatment of ALI/ARDS; unfortunately the major part of these studies did not give any positive result. Nowadays, new therapeutically options and new administration ways have been tested, some of them with promising results. Herein, in this review, the results of several studies in animal models and clinical trials (phase I and II) are extensively revised, giving a summary of all the existing treatments with favorable options. Also, the research in ARDS has been focused in the last decade on the prevention of this disease, trying to decrease mortality and avoid the consequences of undergo this pathology. Recovery of lung alveolar epithelia, reabsorption of edema and regulation of inflammation and coagulation cascades are the best targets to try to resolve ARDS; new preclinical studies should be performed to develop novel therapies and clinical trials should be completed to confirm the obtained positive results.
\end{abstract}

Keywords: Pharmacotherapy; Drugs; Acute respiratory distress syndrome; Acute lung injury; Therapies

\section{Introduction}

Acute Lung Injury (ALI) and its severe form, acute respiratory distress syndrome (ARDS) [1,2], are the most serious causes of acute respiratory failure that are characterized widespread inflammation, severe hypoxemia, decreased lung compliance, and diffuse bilateral infiltrates without evidence of left atrial hypertensionwith formation of no hydrostatic pulmonary edema as a result of breakage of the alveolar-capillary barrier.ALI and ARDS may originate from multiple attacks that damage the lungs directly or indirectly. On the one hand, it develops by pneumonia, acid aspiration, and ischemia/reperfusion after lung transplantation or direct traumatic damage as direct causes or alternatively, and, on the other hand, they may develop secondary to systemic inflammatory diseases such as sepsis, extra pulmonary trauma, transfusion, or cardiopulmonary resuscitation [3-5] (Table 1).

The incidence of ALI is $22-86$ cases per 100,000 persons per year $[6,7]$ and the mortality remains high at $40 \%$ and affects patients of all ages [8]. Despite its high incidence and devastating outcomes, and the recent advances in our understanding of the pathophysiology, ALI/ARDS has no specific treatment and we are focused on treating the underlying disease and preventing secondary lung damage by mechanical ventilation (minimizing potentially harmful ventilation) with low tidal volumes and avoiding a positive fluid balance $[3,8]$.

Damage to the alveolar epithelial barrier is a critical event that occurs in the early phase of the development of ALI/ARDS, associating the severity of epithelial damage to the morbidity and mortality of these patients. The process of repair and the attenuation of inflammatory responses are important aspects for the improvement of patients with ALI/ARDS $[9,10]$.

Moreover, the early phase of ALI/ARDS is characterized by an excessive inflammatory response that results in disruption of the endothelial barrier (Figure 1). As a consequence, a protein-rich lung edema develops and impairs pulmonary function [11]. The pulmonary endothelium is also critically involved in the recruitment and transmigration of polymorphonuclear cells (PMNs) into the lung $[12,13]$. PMNs are the leukocytes that predominantly mediate the initial phase of ALI. Numerous experimental and clinical observations have established a key role for PMNs in the pathogenesis of ALI in animals and patients. ARDS is characterized by breakdown of the alveolarcapillary barrier, leading to flooding of the alveolar space producing the classical chest radiograph of bilateral pulmonary infiltrates (Figure 1).

There is clearly a significant need for improved therapy of ALI/ ARDS, and this review focuses on the potential therapies applied in the last years and the last studies made in relationship with ARDS. We limited this review to the promising potential future pharmacological therapies in ARDS and to the actual randomized control trials [14] (Figure 2).

\section{Anticoagulant or Antiplatelet Agents}

\section{Heparin}

At the early stages of ARDS the presence of proinflammatory mediators downregulate anticoagulant mechanisms and facilitate the propagation of coagulant response. Heparin is a glycosaminoglycan

\begin{tabular}{|c|c|}
\hline Direct Lung Injury & Indirect Lung Injury \\
\hline Pneumonia & Sepsis \\
\hline Aspiration of gastric contents & Burns \\
\hline Pulmonary contusion & Severe trauma with shock \\
\hline Injury by reperfusion or ischemia & Acute pancreatitis \\
\hline Attitude/Drowning & Blood transfusion \\
\hline Inhalation of toxics & Overdose by drugs \\
\hline
\end{tabular}

Table 1: Direct and Indirect causes for acute lung injury (in bold letter the most common triggers).

*Corresponding author: Raquel Guillamat-Prats, Post doc Researcher, Fundació Parc Tauli-CIBERES, Laboratory associates to the Critical Care Center, Parc Taulí, numero 1, Sabadell, Barcelona 08208, Spain, Tel: +34678553768, +34678553768 E-mail: rguillamat@tauli.cat

Received November 28, 2014; Accepted March 16, 2015; Published March 18, 2015

Citation: Guillamat-Prats R, Camprubí-Rimblas M, Artigas A (2015) From Bench to Bedside: Therapies for Acute Respiratory Distress Syndrome. Med chem 5: 108114. doi:10.4172/2161-0444.1000251

Copyright: () 2015 Guillamat-Prats R, et al. This is an open-access article distributed under the terms of the Creative Commons Attribution License, which permits unrestricted use, distribution, and reproduction in any medium, provided the original author and source are credited. 

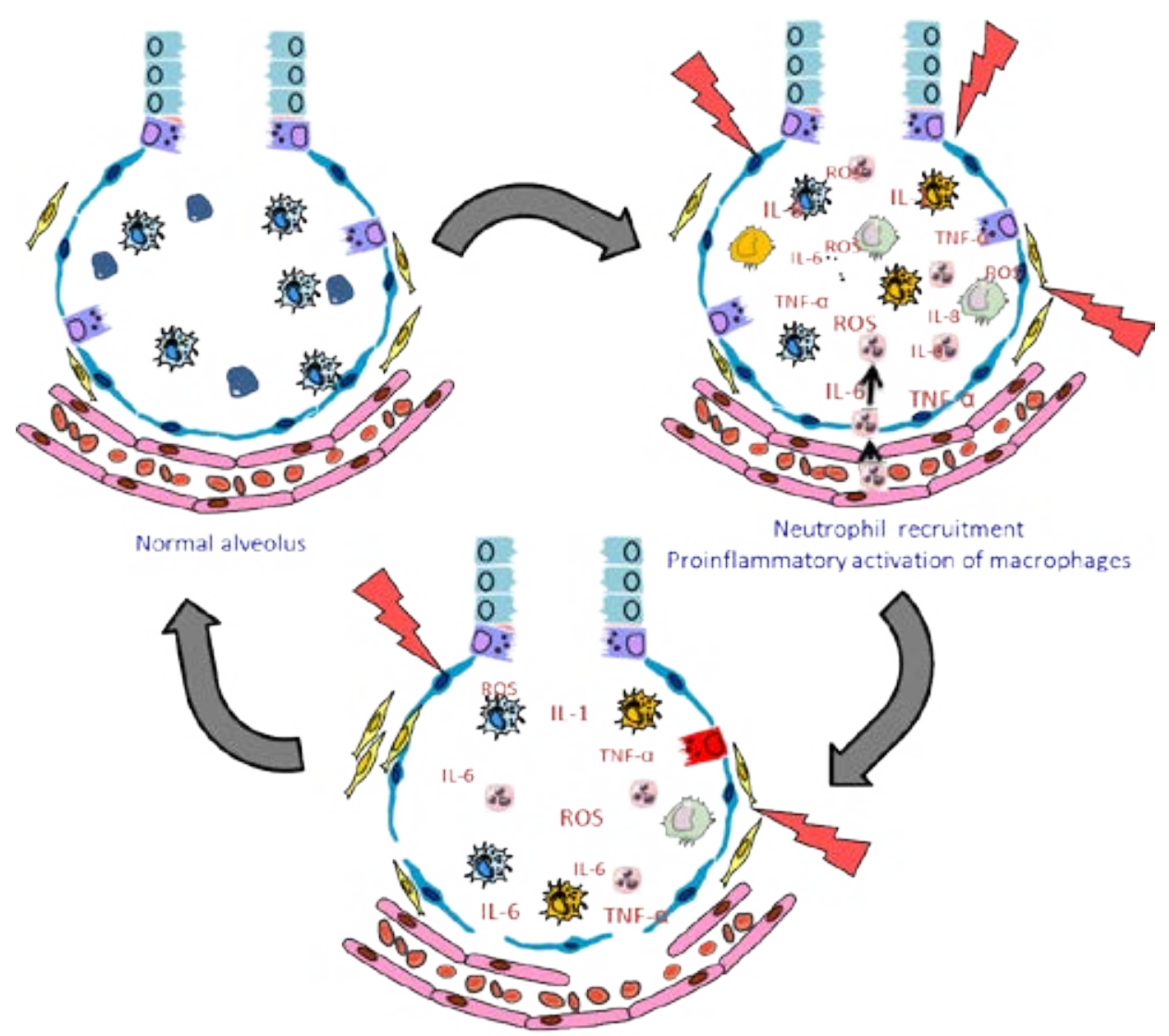

Disruption of alveolar barrier

Injury of alveolar type I and II cells

Interstitial edema and fibrosis

Surfactant inactivation

Figure 1: Physiological basis of acute lung injury and acute respiratory distress syndrome. Acute lung injury is characterized firstly by an increase in the neutrophil recruitment and the proinflammatory activation of macrophages. After that there is a disruption of the alveolar barrier, an injury of the alveolar cells and the marked increase in the volume of fluid and proteins leaving the vascular space, causing pulmonary edema. (ROS= Reactive Oxygen Species).

used in clinical medicine for its anticoagulant properties. Also, this anticoagulant not only has an effect in the process of coagulation and fibrin deposition, moreover heparin is able to modulate the inflammatory process in ARDS binding to proinflammatory cytokines, chemokines and complement factors in a nonspecific manner [15]. Heparin produces systemic effects, so recent studies are focalized on a nebulized heparin administration, which could inhibit the deposition of fibrin casts in the airway and could prevent atelectasis [16].

In some pre-clinical studies it is demonstrated that nebulization of heparin attenuates inflammation and coagulopathies. Hofstra et al. confirmed in his study the positive effect in the pulmonary coagulopathies, but now in inflammation in a rat model of acute lung injury [16].

There are several clinical studies with nebulized heparin administrated to ventilated patients with ARDS. In all these studies it is confirmed that heparin has not any adverse effects and its administration is related to less days of mechanical ventilation $[17,18]$. Further trials are required to investigate and confirm the safety and efficacy of heparin, because data are very limited.

\section{Aspirin}

During ARDS, changes in the coagulation cascade produce an increase in platelet recruitment and the formation of thrombi in the lung. Aspirin is a nonselective inhibitor of the cyclooxygenase pathway and could reduce the formation of fibrin pathological process due to its properties. Observational data obtained showed that aspirin produce a reduction in platelet recruitment and in inflammation. Actually, there are planned different clinical trials to study the effect of heparin in lung coagulation, to evaluate lung inflammation, and with different administration ways and their effect in prevention and therapeutically effect [19]. Pre-injury antiplatelet therapy with aspirin is associated with a decreased risk of lung dysfunction, indicating that aspirin has a role in organ dysfunction development and potential therapeutic implications [20]. No clinical studies giving aspirin as a post-treatment have been carried out.

\section{Anti-inflammatory or Immunomodulators Agents}

\section{Neutrophil elastase inhibitors}

The neutrophil elastase is an enzyme produced by neutrophils that has diverse effects such as antimicrobial action and the restauration of tissue and inflammation, though, an excess of neutrophil elastase can be harmful. Neutrophils play a key role on the ARDS pathophysiology development and neutrophil elastase could damage the endothelia and the alveolar epithelia. In that way giving an inhibitor of neutrophil elastase could be an effective treatment[21]. 


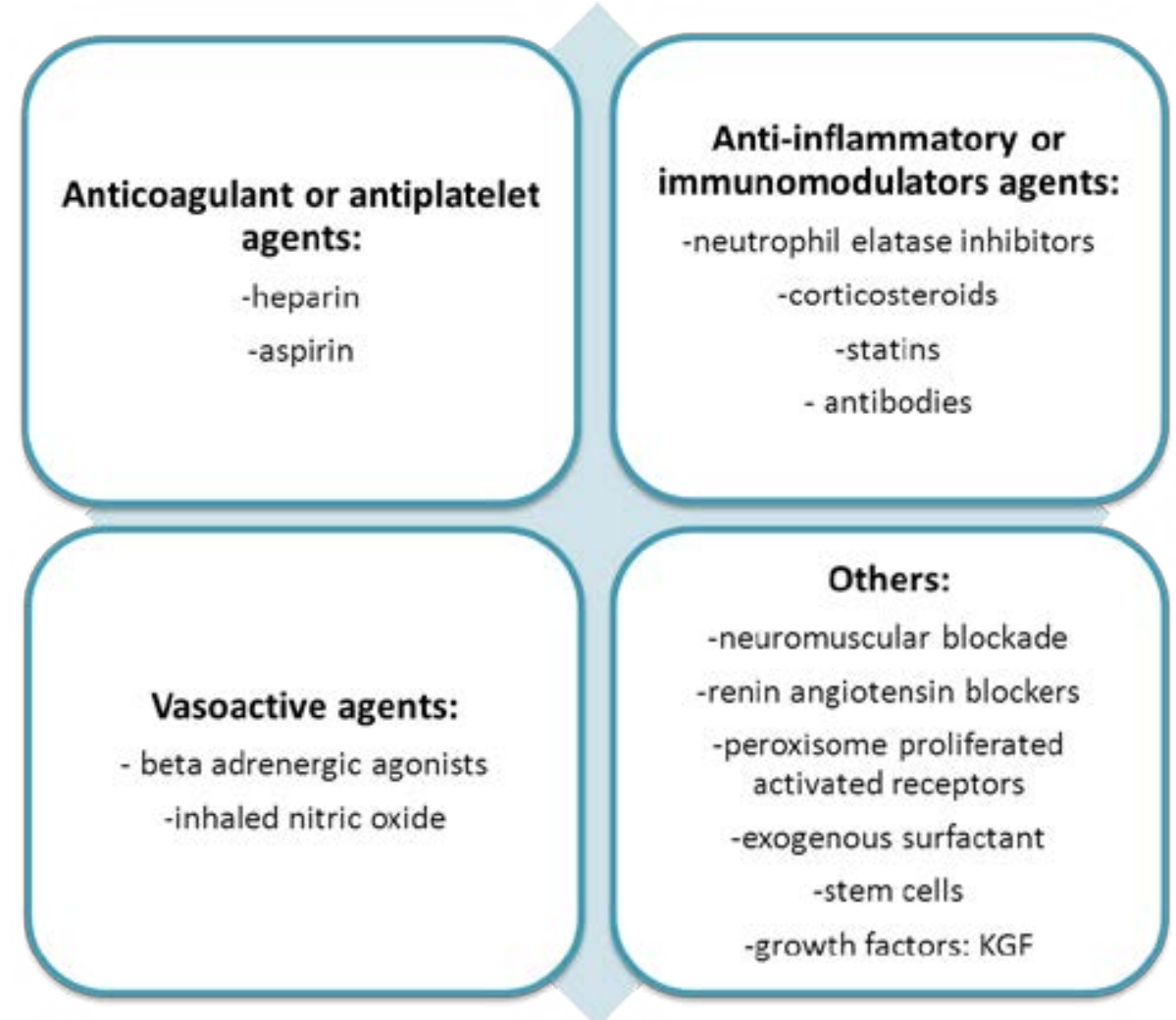

Figure 2: Classification of the therapeutical options.

Some trials have been carried out with a worse outcome for the 180 -day mortality and the majority of these trials have been stopped earlier than expected. In the study of Zeiher et al. intravenous sivelestat, a small molecular weight inhibitor of neutrophil elastase, had no effect on 28-day mortality or in reducing ventilator days in acute lung injury patients [22].

\section{Corticosteroids}

Corticosteroids are multipotent and nonspecific drugs in the interaction with inflammatory cascades with broad inhibitory action on host defenses, including the inhibition of thetranscription of proinflammatory cytokines such as TNF- $\alpha$, IL- $1 \alpha$, IL- $1 \beta$, interferon- $\gamma$, IL-2, IL-3, IL-5, IL- 6, IL-8, IL-12, and granulocyte-macrophage colony-stimulating factor (GM-CSF), also stimulate T-cell, eosinophil, and monocyte apoptosis and additionally inhibit neutrophil activation. Because of these properties, corticosteroids in high doses for a short period were proposed in the early phase of ARDS [23].

A randomized, controlled trial, conducted by the ARDS network, showed no reduction in mortality in the group receiving methylprednisolone, one of the most used corticosteroids. Although, Meduri et al. in other study published that methylprednisolone could reduce the severity of lung injury at day 7 of treatment $[24,25]$. In past studies, corticosteroids did not demonstrate prevention or improvement outcomes of ARDS, and the only positive effect was a reduction in the duration of mechanical ventilation [26-29].

Diverse clinical trials have been performed in the last 10 years, and the last systematic reviews and meta-analysis performed by Dear et al. and Peter et al. exposed that the role of corticosteroids is not clear and further clinical trials have to be performed [30,31].
At the moment, new studies with inhaled corticosteroids for treatment and prevention of ARDS are now in process. All the studies in animal models suggest that there is a reduction of the inflammation, an improvement in pulmonary mechanical and a decrease in hypoxemia. Clinical trials with inhaled corticosteroids are currently ongoing and it is necessary to confirm these results.

\section{Statins}

It is known the role of statins in cholesterol reduction, antiinflammatory actions and endothelial function modulation. Statins are a class of lipid-lowering drug that inhibit 3-hydroxy-threemethylglutaryl coenzyme A reductase [32]. Observational studies of hospitalized patients have associated statins use with a lower risk of developing sepsis, multiple organ dysfunction and mortality [33]. Some observational studies presented controversial results; some of them demonstrated anti-inflammatory effects and a decrease in organ dysfunction with no other adverse effects in the intervention group and others exposed no protective effect or prevention in ARDS, organ failure, duration of mechanical ventilation and other parameters $[32,33]$.

Now, one trial with simvastatinmade in UK and Ireland (HARP-2) has been published in the last month. It demonstrates that simvastatin is safe and associated with minimal adverse effects, but did not improve clinical outcomes in patients with ARDS [34].

Another trial is ongoing in USA (SAILS) with simvastatin and they are recruiting patients and we have to wait for the results.

\section{Anti-TNF-a Antibodies, Anti-IL-8 Antibodies or Anti- CD40L Antibodies}

The three markers have an important role in ARDS. TNF- $\alpha$ is a 
pro-inflammatory cytokine that induces other inflammatory markers and promotes the recruitment of neutrophils to the lung [35,36]; IL-8 is a chemoattractant of neutrophils and it is elevated in ARDS patients [37,38]; CD40L is a receptor expressed in bone marrow cells and in fibroblasts and this receptor is able to induce the production of proinflammatory cytokines when interacts with T lymphocytes $[39,40]$. The use of antibodies anti these three markers has been used in animal models of ARDS and sepsis with positive results; all of them are able to reduce the mortality and the severity of lung injury.

In spite of that, clinical studies with TNF-adid not show any significant improvement. Abraham et al. published in diverse studies thatanti-TNF- $\alpha$ antibody did not decrease mortality in treated group compared with placebo group [41,42].

Cohen et al. suggested a possible role for anti-TNF antibody as adjunctive therapy, but this possibility requires confirmation by others clinical trials [43]. IL-8 and CD40L antibodies were not tested yet in clinical studies.

\section{Vasoactive Agents}

\section{Beta adrenergic agonists}

In ARDS the edema formation is produced by the disruption of the alveolar barrier. Recovery from ARDS requires pulmonary edema resolution, which is driven by active transport of sodium and chloride ions from the luminal space across alveolar epithelial cells, creating an osmotic gradient for the reabsorption of water. Beta 2 agonists increase the rate of transport of salt and water across normal epithelium $[44,45]$.

Experimental data suggest a positive effect of beta adrenergic agonists ( $\beta 2$ agonist) in the alveolar fluid clearance and a decrease in the endothelial permeability. One of the most used beta adrenergic agonists are salbutamol (intravenous) (BALTI-1 and 2) [46,47] or albuterol (nebulized) (ALTA) [48].

In the last five years some trials were carried out testing this two drugs administered intravenous or inhaled in randomized placebocontrolled trials.Nevertheless, all these trials were stopped early due to worsening of patients (the length of the stay was significantly increased and the 28 days mortality also, in the group treated with salbutamol). All these data do not support the use of beta 2 adrenergic agonists and suggest that beta adrenergic agonists may have injurious cardiac effect and may worsen outcome in those patients [49].

\section{Inhaled nitric oxide}

Inhaled nitric oxide (iNO) is an important endogenous mediator in a lot of processes; which has a selective vasodilation effect. The iNO administration reduces systemic effects and has a very short half-life that also minimizes secondary effects [50].

There is a transient improvement in oxygenation in ARDS patients treated with iNO demonstrated by many randomized clinical trials [51-56]. Nevertheless iNO did not reduce mortality in patients with ARDS [52], regardless of the degree of hypoxemia as it is explained in the meta-analysis of [55] Adhikari et al. Summarizing, iNO cannot be recommended for patients with acute hypoxemic respiratory failure because it does notimprove survival benefit and may be harmful, although some subgroups of patients that do not respond to conventional treatments presented significant clinical benefits with iNO.

\section{Others}

\section{Neuromuscular blockade}

Usually, the protective ventilation can be induced in the majority of patients without using any neuromuscular blockade, but, evidently, the administration of these drugs improves the patient-ventilator synchrony[57].

The neuromuscular blockade permits lower-pressure and lower tidal volume ventilation and in consequence a lower injury caused by mechanical ventilation. Forel et al. showed a lower concentration in some proinflammatory markers as IL-1b, IL-6, and IL-8 in treated patients than in the control group and this effect was correlated with a decrease in the 90-days mortality, however, any difference was noted between the group treated and non-treated group until day 20. These results show a promising therapy, but they must be confirmed in a phase-3 trial[58].

The study of Papazian et al. [59] revealed an improvement in oxygenation but the 90 days mortality did not show any significantly statistic difference between cisatracurium group and placebo group [60-62].

\section{Renin angiotensin blockers}

The renin-angiotensin system mediates in the alveolar vasoconstriction, alveolar permeability and fibrosis.Angiotensin-2 up regulates inflammatory pathways through induction of NF-Kb proinflammatory genes. Inhibitors of angiotensin converting enzyme are used to treat hypertension, cerebrovascular disease, heart failure and glomerular disease. Moreover these drugs such as losartan, captopril and perindopril (all of them are inhibitors of angiotensin-converting enzymes) showed positive effects in animal models from acute lung injury [63].

In pre clinical these drugs were able to reduce the risk of develop ARDS. However, these findings were not confirmed in a secondary multicentric clinical study [63].

\section{Peroxisome proliferator activated receptors}

Peroxisome proliferator-activated receptors (PPAR) are pleiotropic transcription factors that have a role in the expression of inflammatory pathways and carbohydrate metabolisms. PPARs have an anti-inflammatory function and therefore it could be useful in the treatment of ARDS [64].

In animal models of acutelung injury induced by LPS administration (intratracheal or endovenous)the PPARs showed promising results. In Schaefer et al. study [65] it was demonstrated a reduce in acute lung injury and vascular leakage as Liu et al. $[66,67]$ studies evidenced a reduction in pulmonary inflammation when rosiglitazone (agonist of PPARs) was administered or when there was a decreased of PPARs levels in lung tissue. Furthemore Delayre-Orthez et al. [68] suggested a beneficial effect in the chronic lung inflammation because of a reduction in cell infiltration, chemoattractant proteins production and higher MMP activity.

At the present time there are no known clinical studies in human using PPAR agonists or ligands.

\section{Exogenous surfactant therapies}

Different kinds of surfactants have been tested: synthetic surfactant with phospholipids, synthetic surfactant with phospholipids and proteins, bovine surfactant and porcine surfactant. Surfactant could be effective enhancing oxygenation and increasing lung ventilated area. In some trials surfactant was administered by aerosolization in continuous or by intratracheal instillation. Gregory et al. published some years ago that bovine surfactant was generally well tolerated; it 


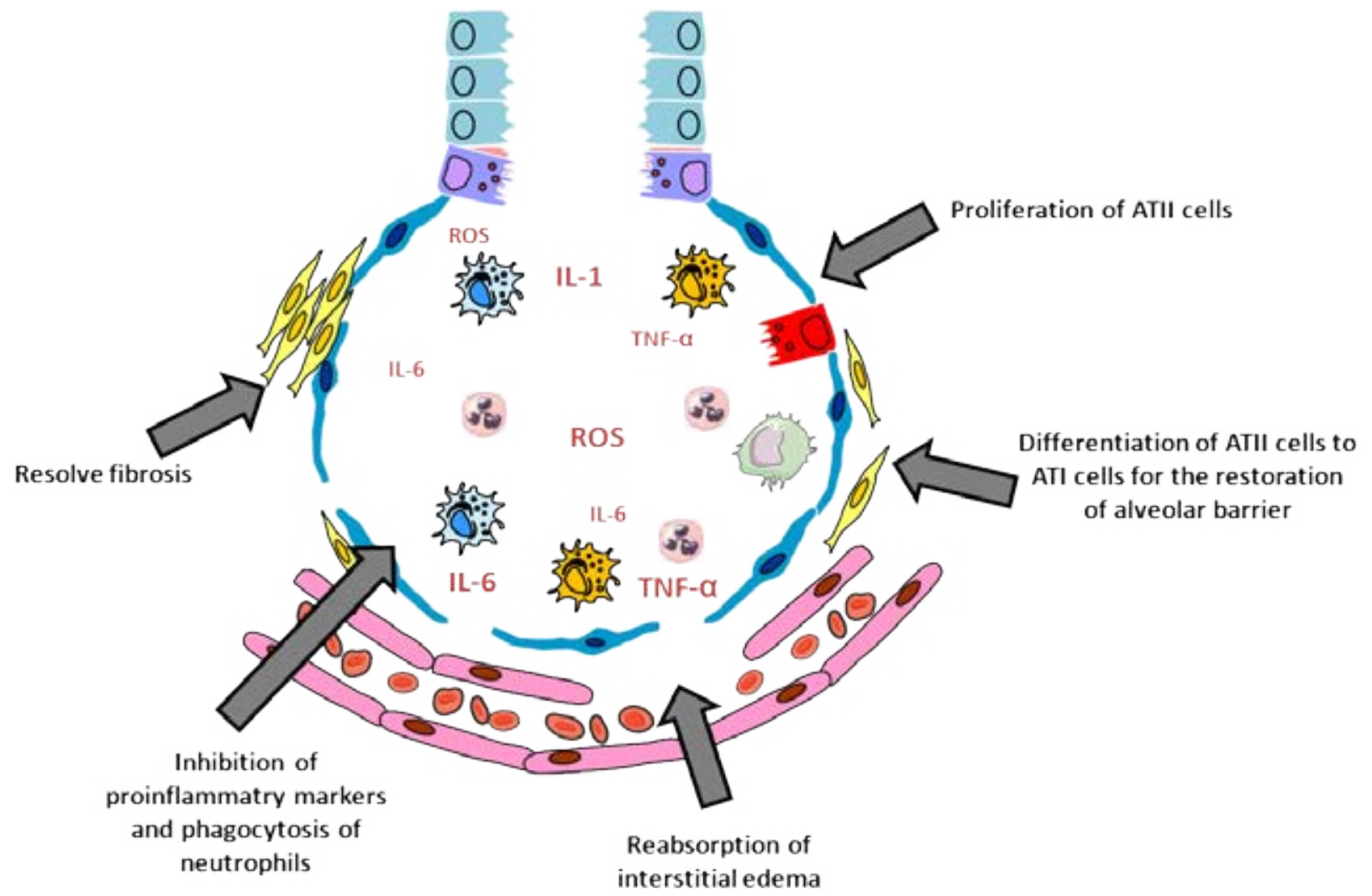

Figure 3: Mechanisms involved in the resolution of acute lung injury and acute respiratory distress syndrome.

was a pilot study with few patients and a post clinical study should be done to confirm these results [69].

On the other hand Anzueto et al. tested continuously administration of aerosolized surfactant in ARDS patients and they did not obtain any significant effect on 30-day survival, duration of mechanical ventilation, or physiologic function [70].

In the last decade other surfactant trials have been made with recombinant surfactants and the results have not shown any significant benefit such as the study of Spragg et al. revealed [71].

\section{Stem cell therapy}

Cell therapies are new potential therapies that try to repair the tissue injured. Moreover it is well-described the immunomodulatory effect of stem cells that may release some factors which have a paracrine effect that induces the recovery of the lung tissue. Stem cells have been tested in animal models with acute lung injury and the results obtained are really promising $[72,73]$. Clinical trials may be performed; the group of Dr. M. Matthay will start a preclinical study to evaluate the security of the administration of these stem cells in ARDS patients [74].

\section{Growth factors: Keratinocyte growth factors}

Keratinocyte Growth Factors (KGF) has an effect on alveolar type II proliferation, and these cells are actively implicated in the repair of damage in lung [75]. KGF is secreted by fibroblasts such as other mediators and all of them are implicated in the recovery of injured lung. A preclinical study was made with KGF with positive results and now the phase II trial will start [76].

\section{Other}

Furthermore other small phase I and phase II clinical trials are in progress. New designed or old designed drugs that have effect on stop some proinflammatory pathways such as p28alpha (MAP kinase), interferon beta or coagulation factor III. All these studies are now ingoing and the results of safety and efficacy will be given in the next months.

\section{Conclusion}

Recent data shows that mortality is near $40 \%$ in ARDS patient and has adverse outcomes [6-8]; there is no question that new therapeutical approximations have to been found. The number of clinical trials testing new pharmacological therapies for ARDS has increased in the last years and some of them have encouraging results. Other clinical trials are now in progress. All of these new tested drugs are focused on reduce lung inflammation and enhance alveolar reparation (Figure 3).

In this review we summarized some of the most interesting treatments and with more therapeutic potential effect for the treatment of ARDS and include the most relevant bibliography of these studies and clinical trials. However, new preclinical and clinical trials should be performed to confirm the positive results or find new therapies.

\section{References}

1. Rubenfeld GD, Caldwell E, Peabody E, Weaver J, Martin DP, et al. (2005) Incidence and outcomes of acute lung injury. N Engl J Med 353: 1685-1693.

2. Bernard GR, Artigas A, Brigham KL, Carlet J, Falke K, et al. (1994) Report of the American-European Consensus conference on acute respiratory distress syndrome: definitions, mechanisms, relevant outcomes, and clinical trial coordination. Consensus Committee. J Crit Care 9: 72-81.

3. Ware LB, Matthay MA (2000) The acute respiratory distress syndrome. N Eng J Med 342: 1334-1349.

4. Cohen TS, DiPaolo BC, Lawrence GG, Margulies SS (2012) Sepsis enhances 
epithelial permeability with stretch in an actin dependent manner. PLoS One 7: e38748.

5. Cirino G, Napoli C, Bucci M, Cicala C (2000) Inflammation-coagulation network: are serine protease receptors the knot? Trends Pharmacol Sci 21: 170-172.

6. Hudson LD, Milberg JA, Anardi D, Maunder RJ (1995) Clinical risks for development of the acute respiratory distress syndrome. Am J Respir Crit Care Med 151: 293-301.

7. Johnston CJ, Rubenfeld GD, Hudson LD (2003) Effect of age on the development of ARDS in trauma patients. Chest 124: 653-659.

8. Eisner MD, Thompson T, Hudson LD, Luce JM, Hayden D, et al. (2001) Efficacy of low tidal volume ventilation in patients with different clinical risk factors for acute lung injury and the acute respiratory distress syndrome. Am J Respir Crit Care Med 164: 231-236.

9. Ware LB, Matthay MA, Parsons PE, Thompson BT, Januzzi JL, et al. (2007) The National Heart, Lung, and Blood Institute Acute Respiratory Distress Syndrome Clinical Trials Network. Pathogenetic and pronostic significance of altered coagulation and fibrinolysis in acute lung injury/ acute respiratory distress syndrome. Crit Care Med 35: 8.

10. Günther A, Mosavi P, Heinemann S, Ruppert C, Muth H, et al. (2000) Alveolar fibrin formation caused by enhanced procoagulant and depressed fibrinolytic capacities in severe pneumonia. Comparison with the acute respiratory distress syndrome. Am J Respir Crit Care Med 161: 454-462.

11. Matthay MA, Zimmerman GA (2005) Acute lung injury and the acute respiratory distress syndrome: four decades of inquiry into pathogenesis and rational management. Am J Respir Cell Mol Biol 33: 319-327.

12. Pugin J, Verghese G, Widmer MC, Matthay MA (1999) The alveolar space is the site of intense inflammatory and profibrotic reactions in the early phase of acute respiratory distress syndrome. Crit Care Med 27: 304-312.

13. Zemans RL, Colgan SP, Downey GP (2009) Transepithelial migration of neutrophils: mechanisms and implications for acute lung injury. Am J Respir Cell Mol Biol 40: 519-535

14. Johnson ER, Matthay MA (2010) Acute lung injury: epidemiology, pathogenesis, and treatment. J Aerosol Med Pulm Drug Deliv 23: 243-252.

15. Tuinman PR, Dixon B, Levi M, Juffermans NP, Schultz MJ (2012) Nebulized anticoagulants for acute lung injury - a systematic review of preclinical and clinical investigations. Crit Care 16: R70.

16. Hofstra JJ, Vlaar AP, Cornet AD, Dixon B, Roelofs JJ, et al. (2010) Nebulized anticoagulants limit pulmonary coagulopathy, but not inflammation, in a model of experimental lung injury. J Aerosol Med Pulm Drug Deliv 23: 105-111.

17. Dixon B, Santamaria JD, Campbell DJ (2008) A phase 1 trial of nebulised heparin in acute lung injury. Crit Care 12: R64.

18. Dixon B, Schultz MJ, Smith R, Fink JB, Santamaria JD, et al. (2010) Nebulized heparin is associated with fewer days of mechanical ventilation in critically ill patients: a randomized controlled trial. Crit Care 14: R180.

19. Harr JN, Moore EE, Johnson J, Chin TL, Wohlauer MV, et al. (2013) Antiplatelet therapy is associated with decreased transfusion-associated risk of lung dysfunction, multiple organ failure, and mortality in trauma patients. Crit Care Med 41: 399-404.

20. O'Neal HR Jr, Koyama T, Koehler EA, Siew E, Curtis BR, et al. (2011) Prehospital statin and aspirin use and the prevalence of severe sepsis and acute lung injury/acute respiratory distress syndrome. Crit Care Med 39: 13431350.

21. Gehrig S, Duerr J, Weitnauer M, Wagner CJ, Graeber SY, et al. (2014) Lack of neutrophil elastase reduces inflammation, mucus hypersecretion, and emphysema, but not mucus obstruction, in mice with cystic fibrosis-like lung disease. Am J Respir Crit Care Med 189: 1082-1092.

22. Zeiher BG, Artigas A, Vincent JL, Dmitrienko A, Jackson K, et al. (2004) Neutrophil elastase inhibition in acute lung injury: results of the STRIVE study. Crit Care Med 32: 1695-1702.

23. Thompson BT1 (2003) Glucocorticoids and acute lung injury. Crit Care Med 31: S253-257.

24. Steinberg KP, Hudson LD, Goodman RB, Hough CL, Lanken PN, et al. (2006) Efficacy and safety of corticosteroids for persistent acute respiratory distress syndrome. N Engl J Med 354: 1671-1684.

25. Meduri GU, Golden E, Freire AX, Taylor E, Zaman M, et al. (2007)
Methylprednisolone infusion in early severe ARDS: results of a randomized controlled trial. Chest 131: 954-963.

26. Sprung CL, Caralis PV, Marcial EH, Pierce M, Gelbard MA, et al. (1984) The effects of high-dose corticosteroids in patients with septic shock. A prospective controlled study. N Engl J Med 311: 1137-1143.

27. Luce JM, Montgomery AB, Marks JD, Turner J, Metz CA, et al. (1988) Ineffectiveness of high-dose methylprednisolone in preventing parenchymal lung injury and improving mortality in patients with septic shock. Am Rev Respir Dis 138: 62-68.

28. Weigelt JA, Norcross JF, Borman KR, Snyder WH 3rd (1985) Early steroid therapy for respiratory failure. Arch Surg 120: 536-540.

29. Bernard GR, Luce JM, Sprung CL, Rinaldo JE, Tate RM, et al. (1987) Highdose corticosteroids in patients with the adult respiratory distress syndrome. $\mathrm{N}$ Engl J Med 317: 1565-1570.

30. Deal EN, Hollands JM, Schramm GE, Micek ST (2008) Role of corticosteroids in the management of acute respiratory distress syndrome. Clin Ther 30: 787799.

31. Peter JV, John P, Graham PL, Moran JL, George IA, et al. (2008) Corticosteroids in the prevention and treatment of acute respiratory distress syndrome (ARDS) in adults: meta-analysis. BMJ 336: 1006-1009.

32. O'Neal HR Jr, Koyama T, Koehler EA, Siew E, Curtis BR, et al. (2011) Prehospital statin and aspirin use and the prevalence of severe sepsis and acute lung injury/acute respiratory distress syndrome. Crit Care Med 39: 13431350.

33. Bajwa EK, Malhotra CK, Thompson BT, Christiani DC, Gong MN (2012) Statin therapy as prevention against development of acute respiratory distress syndrome: an observational study. Crit Care Med 40: 1470-1477.

34. McAuley DF, Laffey JG, O'Kane CM, Perkins GD, Mullan B, et al. (2014) Simvastatin in the acute respiratory distress syndrome. N Engl J Med 371 1695-1703.

35. Tracey KJ, Fong Y, Hesse DG, Manogue KR, Lee AT, et al. (1987) Anticachectin/TNF monoclonal antibodies prevent septic shock during lethal bacteraemia. Nature 330: 662-664.

36. Li XY, Donaldson K, Brown D, MacNee W (1995) The role of tumor necrosis factor in increased airspace epithelial permeability in acute lung inflammation. Am J Respir Cell Mol Biol 13: 185-195.

37. Yokoi K, Mukaida N, Harada A, Watanabe Y, Matsushima K (1997) Prevention of endotoxemia-induced acute respiratory distress syndrome-like lung injury in rabbits by a monoclonal antibody to IL-8. Lab Invest 76: 375-384.

38. Broaddus VC, Boylan AM, Hoeffel JM, Kim KJ, Sadick M, et al. (1994) Neutralization of IL-8 inhibits neutrophil influx in a rabbit model of endotoxininduced pleurisy. J Immunol 152: 2960-2967.

39. Adawi A, Zhang $Y$, Baggs R, Rubin P, Williams J, et al. (1998) Blockade of CD40-CD40 ligand interactions protects against radiation-induced pulmonary inflammation and fibrosis. Clin Immunol Immunopathol 89: 222-230.

40. Adawi A, Zhang Y, Baggs R, Finkelstein J, Phipps RP (1998) Disruption of the CD40-CD40 ligand system prevents an oxygen-induced respiratory distress syndrome. Am J Pathol 152: 651-657.

41. Abraham E, Wunderink R, Silverman H, Perl TM, Nasraway S, et al. (1995) Efficacy and safety of monoclonal antibody to human tumor necrosis factor alpha in patients with sepsis syndrome. A randomized, controlled, double-blind, multicenter clinical trial. TNF-alpha MAb Sepsis Study Group. JAMA 273: 934 941.

42. Abraham E, Anzueto A, Gutierrez G, Tessler S, San Pedro G, et al. (1998) Double-blind randomized controlled trial of monoclonal antibody to human tumour necrosis factor in treatment of septic shock. NORASEPT II Study Group. Lancet. 351: 929-933.

43. Cohen J, Carlet J (1996) INTERSEPT: an international, multicenter, placebocontrolled trial of monoclonal antibody to human tumor necrosis factor-alpha in patients with sepsis. International Sepsis Trial Study Group. Crit Care Med 24: $1431-1440$.

44. Matthay MA, Folkesson HG, Clerici C (2002) Lung epithelial fluid transport and the resolution of pulmonary edema. Physiol Rev 82: 569-600.

45. Perkins GD, McAuley DF, Richter A, Thickett DR, Gao F (2004) Bench-tobedside review: beta2-Agonists and the acute respiratory distress syndrome. Crit Care 8: 25-32 
46. Perkins GD, McAuley DF, Thickett DR, Gao F (2006) The beta-agonist lung injury trial (BALTI): a randomized placebo-controlled clinical trial. Am J Respir Crit Care Med 173: 281-287.

47. Smith FG, Perkins GD, Gates S, Young D, McAuley DF, et al. (2012) BALTI-2 study investigators: Effect of intravenous B -2 agonist treatment on clinical outcomes in acute respiratory distress syndrome (BALTI-2): a multicentre, randomised controlled trial. Lancet 379: 229- 235

48. National Heart, Lung, and Blood Institute Acute Respiratory Distress Syndrome (ARDS) Clinical Trials Network, Matthay MA, Brower RG, et al. (2011) Randomized, placebo-controlled clinical trial of an aerosolized Î̃â,,-agonist for treatment of acute lung injury. Am J Respir Crit Care Med 184: 561-568.

49. Singh B, Tiwari AK, Singh K, Singh SK, Ahmed A, et al. (2014) î22 agonist for the treatment of acute lung injury: a systematic review and meta-analysis. Respir Care 59: 288-296.

50. Taylor RW, Zimmerman JL, Dellinger RP, Straube RC, Criner GJ, et al. (2004) Low-dose inhaled nitric oxide in patients with acute lung injury: a randomized controlled trial. JAMA 291: 1603-1609.

51. Michael JR, Barton RG, Saffle JR, Mone M, Markewitz BA, et al. (1998) Inhaled nitric oxide versus conventional therapy: effect on oxygenation in ARDS. Am J Respir Crit Care Med 157: 1372-1380.

52. Dellinger RP, Zimmerman JL, Taylor RW, Straube RC, Hauser DL, et al. (1998) Effects of inhaled nitric oxide in patients with acute respiratory distress syndrome: results of a randomized phase II trial. Inhaled Nitric Oxide in ARDS Study Group. Crit Care Med 26: 15-23.

53. Troncy E, Collet JP, Shapiro S, Guimond JG, Blair L, et al. (1998) Inhaled nitric oxide in acute respiratory distress syndrome: a pilot randomized controlled study. Am J Respir Crit Care Med 157: 1483-1488.

54. Lundin S, Mang H, Smithies M, Stenqvist O, Frostell C (1999) Inhalation of nitric oxide in acute lung injury: results of a European multicentre study. The European Study Group of Inhaled Nitric Oxide. Intensive Care Med 25: 911 919.

55. Adhikari NK, Dellinger RP, Lundin S, Payen D, Vallet B, et al. (2014) Inhaled nitric oxide does not reduce mortality in patients with acute respiratory distress syndrome regardless of severity: systematic review and meta-analysis. Crit Care Med 42: 404-412.

56. Afshari A, Brok J, MÃ,ller AM, Wetterslev J (2011) Inhaled nitric oxide for acute respiratory distress syndrome and acute lung injury in adults and children: a systematic review with meta-analysis and trial sequential analysis. Anesth Analg 112: 1411-1421.

57. Slutsky AS (2010) Neuromuscular blocking agents in ARDS. N Engl J Med 363: 1176-1180.

58. Forel JM, Roch A, Marin V, Michelet P, Demory D, et al. (2006) Neuromuscular blocking agents decrease inflammatory response in patients presenting with acute respiratory distress syndrome. Crit Care Med 34: 2749-2757.

59. Papazian L, Forel JM, Gacouin A, Penot-Ragon C, Perrin G, et al. (2010) Neuromuscular blockers in early acute respiratory distress syndrome. $\mathrm{N}$ Engl J Med 363: 1107-1116.

60. Lagneau F, D honneur G, Plaud B, Mantz J, Gillart T, et al. (2002) A comparison of two depths of prolonged neuromuscular blockade induced by cisatracurium in mechanically ventilated critically ill patients. Intensive Care Med 28: 17351741.

61. Gainnier M, Roch A, Forel JM, Thirion X, Arnal JM, et al. (2004) Effect of neuromuscular blocking agents on gas exchange in patients presenting with acute respiratory distress syndrome. Crit Care Med 32: 113-119.
62. Neto AS, Pereira VG, EspÃ $\tilde{s}^{3}$ ito DC, Damasceno MC, Schultz MJ (2012) Neuromuscular blocking agents in patients with acute respiratory distress syndrome: a summary of the current evidence from three randomized controlled trials. Ann Intensive Care 2: 33

63. Trillo-Alvarez CA, Kashyap R, Kojicic M G. Li, Thakur S, Cartin-Ceba R, et al. (2009) Chronic Use of Angiotensin Pathway Inhibitors Is Associated with a Decreased Risk of Acute Respiratory Distress Syndrome American Journal Respiratory Critical Care Medicine 179: A4638 abstract (Thematic poster)

64. Cuzzocrea S1 (2006) Peroxisome proliferator-activated receptors and acute lung injury. Curr Opin Pharmacol 6: 263-270.

65. Schaefer MB, Pose A, Ott J, Hecker M, Behnk A, et al. (2008) Peroxisome proliferator-activated receptor-alpha reduces inflammation and vascular leakage in a murine model of acute lung injury. Eur Respir J 32: 1344-1353.

66. Liu D, Zeng BX, Zhang SH, Wang YL, Zeng L, et al. (2005) Rosiglitazone, a peroxisome proliferator-activated receptor-gamma agonist, reduces acute lung injury in endotoxemic rats. Crit Care Med 33: 2309-2316.

67. Liu D, Zeng BX, Shang Y (2006) Decreased expression of peroxisome proliferator-activated receptor gamma in endotoxin-induced acute lung injury. Physiol Res 55: 291-299.

68. Delayre-Orthez C, Becker J, Guenon I, Lagente V, Auwerx J, et al. (2005) PPARalpha downregulates airway inflammation induced by lipopolysaccharide in the mouse. Respir Res 6: 91.

69. Gregory TJ, Steinberg KP, Spragg R, Gadek JE, Hyers TM, et al. (1997) Bovine surfactant therapy for patients with acute respiratory distress syndrome. Am J Respir Crit Care Med 155: 1309-1315.

70. Anzueto A, Baughman RP, Guntupalli KK, Weg JG, Wiedemann HP, et al. (1996) Aerosolized surfactant in adults with sepsis-induced acute respiratory distress syndrome. Exosurf Acute Respiratory Distress Syndrome Sepsis Study Group. N Engl J Med 334: 1417-1421.

71. Spragg RG, Lewis JF, Wurst W, HÃufner D, Baughman RP, et al. (2003) Treatment of acute respiratory distress syndrome with recombinant surfactant protein C surfactant. Am J Respir Crit Care Med 167: 1562-1566.

72. Gupta N, Su X, Popov B, Lee JW, Serikov V, et al. (2007) Intrapulmonary delivery of bone marrow-derived mesenchymal stem cells improves survival and attenuates endotoxin-induced acute lung injury in mice. J Immunol 179: 1855-1863.

73. Lee JW, Krasnodembskaya A, McKenna DH, Song Y, Abbott J, et al. (2013) Therapeutic effects of human mesenchymal stem cells in ex vivo human lungs injured with live bacteria. Am J Respir Crit Care Med 187: 751-760.

74. Liu KD, Wilson JG, Zhuo H Caballero L, McMillan M, Fang X, et al. (2014) Design and implementation of the START (STem cells for ARDS Treatment) trial, a phase $1 / 2$ trial of human mesenchymal stem/stromal cells for the treatment of moderate-severe acute respiratory distress syndrome. Annals of Intensive Care. In press.

75. Ware LB, Matthay MA (2002) Keratinocyte and hepatocyte growth factors in the lung: roles in lung development, inflammation, and repair. Am J Physiol Lung Cell Mol Physiol 282: L924-940.

76. Cross LJ, O'Kane CM, McDowell C, Elborn JJ, Matthay MA, et al. (2013) Keratinocyte growth factor in acute lung injury to reduce pulmonary dysfunction-a randomised placebo-controlled trial (KARE): study protocol. Trials 14: 51. 